Aptículo de INVestigactón / Research apticie

\section{La República en Colombia desde el ideal de Platón, lean Bodino y Emmanuel Kant}

The Republic in Colombia from the Platon, Jean Bodino and Emmanuel Kant's ideal

Valeria Esther Guerrere -

RECIBDD: 08-12-16 ACEPTAD: 15-01-16 PUBLCADO: 09-01-17

\section{Resumen}

La Asamblea Nacional Constituyente en Colombia nace de una iniciativa ciudadana en 1989 liderada por

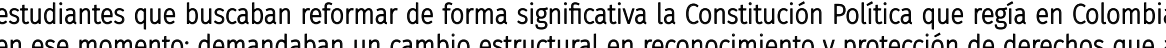
su vez, exigía la consolidación del Estado social de Derecho, una ciudadanía participativa y una ideal forma de gobierno: la Republica, Con base en que argumentos? La investigación se cuestionó sobre la cercania por parte de tres ilustres pensadores,-Platón lean Bodino y Emmanuel Kant- para en últimas, contrastar dilucidar similitudes o brechas distanciadoras entre ellos.

Iabras clave: República, rep

Abstract

The National Constituent Assembly in Colombia was born out of a citizens' initiative in 1989 inspired by students who sought to significantly reform the Political Constitution that governed Colombia at that the consolidation of the social state of law, a participatory citizenship afd an iseal form of sorernmed the Republic, based on what arguments? The research questioned the closeness between the republican discourse assumed by the constituent and the approach of the same notion on the part of three illustrious distancing gaps between them

Tey words: Republic, Republicanism, Constitution, State, Nation.

\section{INTRODUCCIÓN}

¿Qué pueden tener en común un campesino en el Cauca, un músico de la costa Caribe, un ejecutivo de la la metrópolis bogotana o un pescador en el Chocó? La colombianidad no está sujeta a oficios o lugares de asentamiento en el país, es un arraigo colectivo por una historia compartida: la historia de Colombia.

Esta historia aborda muchos personajes y situaciones, pero solo las más trascendentes definieron nuestra idea de Estado y nación, y son precisamente estos factores los justificantes de las estructuras sociales en las que convivimos y los parámetros gubernamentales en que nos regimos, de ah la impotancia de conocer y reconocer los porqués de nuestras instituciones, pues su desconocimiento desemboca en discordias absurdas, patrias bobas que al no justificar sus fines de fondo, debaten por formas inconvenientes.

En curso de esta Historia en común, ocurrió un suceso de no poca importancia: el acontecido el 4 de julio de 1991. Ese día, mediante una transmisión de televisión, los colombianos escucharon asombrados el coro de El Mesías, de Händel, mientras los miembros de la Asamblea Nacional Constituyente, uno a uno, firmaban la nueva Constitución Política de Colombia en el Capitolio Nacional. (Banco de la República, 2016). Una Constitución redactada bajo los ideales de libertad, igualdad y dignidad humana, expresiones esperanzadoras y casi soñadas, en medio de una violencia ${ }^{4}$ ensordecedora que afectaba directa o indirectamente a todos los colombianos.

Una Constitución llamada al cambio, que se distinguió de sus predecesoras desde el preámbulo hasta el final, que buscaba la protección efectiva de los derechos, balancear los pesos y contrapesos en la estructura del Estado, y una participación incluyente y real de toda la ciudadanía. Este texto de aproximadamente 380 artículos fue cuidadosamente redactado y discutido por 74 constituyentes escogidos democráticamente, pero lejos de ser un órgano colegiado cualquiera, en esta Asamblea estaban realmente representados los diversos sectores sociales y culturales de la Nación, una Nación

3 Haciendo refrencia

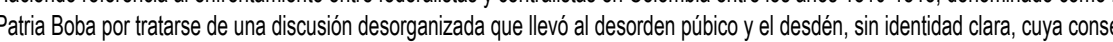
cuencia néfasta fue la reconnuista de la corona española

1989-1991, Periodo de auge del narcotááfico en Colombia, que desencadenó mútiples muertes violentas y ortas inminentes manifestaciones de alienación de derechos. 
que comenzaba a reconocerse a sí misma y a su diversidad, y por tanto, a reconocer sus propios derechos.

La Asamblea Nacional Constituyente de 1991 germinó de un movimiento estudiantil que aclamaba una reforma constitucional exhaustiva, y justo esa comunidad de estudiantes, que hasta entonces fue un sector apático de la política y la realidad nacional, (Ripoll, 2016) fue quien abanderó la iniciativa de votar por la conformación de una Asamblea que redactara una nueva Constitución, que no fuese ajena a los tiempos difíciles que atravesaban, que protegiera a los colombianos más vulnerables, que reconociera con claridad derechos individuales y colectivos, una Asamblea a la que los colombianos dijeran sí, en una última y Séptima papeleta en las elecciones próximas de aquel entonces, en el año de 1989.

Uno de los puntos debatidos en el curso de la redacción de esta Carta Política fue el contenido que tendría el artículo primero, la entrada de esta nueva y prometedora Constitución:

Artículo 10.Colombia es un Estado social de derecho, organizado en forma de República unitaria, descentralizada, con autonomía de sus entidades territoriales, democrática, participativa y pluralista, fundada en el respeto de la dignidad humana, en el trabajo y la solidaridad de las personas que la integran y en la prevalencia del interés general. (Centro de Documentación Judicial Corte Constitucional, 2015)

Bajo la luz de este artículo, Colombia sería llamada República, pero, ¿Qué signficaba ser una República? ¿Por qué y cómo se decidió que Colombia sería una República? El Constituyente, por ser el redactor de este artículo, es el responsable de que asi esté organizada Colombia, y es en sus debates donde es posible dilucidar sus motivos para acoger la noción republicana; desentrañar estos motivos fue el propósito magno de esta investigación, pero no de forma aislada, sino, a partir del enfoque dado por Platón, Jean Bodino y Emmanuel Kant, en cuanto a formas de gobierno se tratáse.

Fueron escogidos estos pensadores, dado que en sus obras La República, Los Seis Libros de la República y La Paz Perpetua, respectivamente, concentran con especial riqueza descriptiva su idea republicana para gobernar, según la etapa histórica en que cada uno de ellos vivió, pues aunque se pudo escoger pensadores de la edad moderna como comúnmente se relaciona al hablar de República, en lugar de ello, se pensó en explorar su concepción en tiempos distintos, realidades distintas.

Con base en la anterior premisa, se planteó una consecuente pregunta problema: ¿Cómo se relaciona la noción republicana contenida en la Constitución de 1991 según las ideas de Platón, Jean Bodino y Emmanuel Kant?

\section{METODOLOGIA}

En las actas de la Asamblea Nacional Constiuyente, en la Constitución resultante y en los trabajos de investigación consecuentes, se halla el espíritu y razón der ser de los artículos de la Constitución, su revisión se convierte así, en el método idóneo para hallar respuesta a las preguntas planteadas.

En consecuencia, el equipo investigador a cargo de esta propuesta se dispuso a examinar cuidadosamente los documentos reseñados (Actas de la Asamblea Nacional Constituyente, documentos de investigación referentes al tema en colación, Constitución Política de 1991, en ese orden respectivamente).

En curso de la lectura exploratoria que realiza el equipo, se resaltan y separan con el fin de leer nuevamente, toda la información que se relacione con el problema planteado, esta vez con un enfoque hermenéutico histórico bajo la modalidad cualitativa, es decir, en búsqueda de factores determinantes, posibles de describir, que dieran respuesta a las preguntas problema enunciadas anteriormente, interpretando el sentido en que dichas intervenciones eran propuestas según el contexto histórico. Esta revisión fue hecha con mayor rigurosidad en la Constitución Política de 1991, que inicialmente era nuestro punto de partida, no obstante, al ser escasos los insumos descriptivos aportados por esta, nos obligó a remitirnos a la Constitución Política de 1886 y sus reformas.

Posterior a ello, se recurrió a la lectura concienzuda de las obras: Los seis libros de la República de Jean Bodino, La República de Platón y La paz perpetua de Kant, resaltando las características republicanas que enunciaba cada obra así, contrastar al final sus ideales con los contemplados en la Constitución Política colombiana actual. 
En ejecución de la anterior metodología trazada, se obtuvieron los siguientes resultados:

\section{PRECEPTOS REPUBLICANOS ACOGIDOS POR LA CONSTITUCIÓN DE 1991.}

Ya lo aseveró nuestra Constitución Política iniciando apenas su redacción y lectura: Colombia sería llamada República, teniendo esta como primer nombre, sin embargo, ¿Contaba el Constituyente con los presupuestos filosóficos, históricos, jurídicos, o acaso sociales, para denominarla de esta manera?, ¿Es el ciudadano de hoy, consciente de lo que implica pertenecer a una República? Inquietudes como estas nos remiten a reunir todo lo necesario, en el marco de una revisión bibliográfica, sobre la definición que acogió el Constituyente hace un cuarto de siglo y lo que pretendió al hacerlo.

Citado por los Constituyentes Hernando Herrera Antonio Navarro Wolf, José Matías Artiz y Fabel Rodríguez, el concepto dado por Ángel Rivero, supone una aproximada y acertada forma de definir la República, así:

Un régimen político en el que, al mismo tiempo que se garantizaba la participación popular en el gobierno, se conjuraba el peligro que para la libertad y la justicia representaba la democracia pura, esto es, la democracia ateniense. Es decir, los conceptos de democracia y república referían a formas de gobierno distintas y hasta opuestas. (Ortiz Leroux, 2007, pág. 52)

La manifestación del constituyente, (que es primaria, incondicionada, autónoma y superior) fue que Colombia (que pasó por varios nombres y por muchas dimensiones), se organizara del modo en que hoy la conocemos, y aunque fueron múltiples las constituciones precedentes a la actual, la más próxima a ella genera singular controversia, dadas las diferencias abismales en ideales, axiología y dogmática con su predecesora. Nos referimos a la Constitución Política de 1886

\section{La República en la Constitución Política de 1886.}

Bolívar mismo, ante el infortunio de la separación de su Gran Colombia, catalogaba desde entonces a Colombia y sus pares, Ecuador y Venezuela, como repúblicas, que inminentemente tomarían cada una, un rumbo completamente distinto, puede que con un común denominador que agoniza a las Américas del Sur por igual, pero no es este tema a discusión; lo es en cambio, determinar, las secuelas históricas que dieron pie a la creación de una Constitución en medio de tan turbulento contexto como lo fue la Colombia de 1886, y a su vez, enmarcar sus estamentos dentro del discurso republicano que tanto aludían sus próceres.

Algunas de las bases de la reforma constitucional, que derogó la Constitución de Rionegro (1863), para darle paso al Consejo Nacional de Delegatarios 5 fue:

\section{a La soberania reside única exclusivamente en la Nación, que se}

denominará República de Colombia. (Tascón, 2000)

\section{Antecedentes de investigación.}

Es recordada como la República conservadora, aquella Colombia en el S. XIX que se regía bajo incisos cambiantes, pero a la vez, atemporales, como la estrecha cercanía con la Iglesia Católica, el proteccionismo económico o la tendencia poblacional a habitar en el campo.

La organización política, administrativa y fiscal vigente en la República hasta la coyuntura reformadora del medio siglo creó la imagen artificiosa de la existencia de un espacio económico y político unitario y centralizado; esto condujo a creer en la existencia política de la nación desde el comienzo mismo de la vida independiente (Uribe, 1987).

La Constitución colombiana de 1886 estuvo influenciada por un marcado sentimiento libertario, en el que se quiso resguardar el bienestar de los trabajadores y reunificar las ideas dentro del Estado, sin embargo, llegar a este punto no fue fácil, el país era golpeado por uno de los conflictos más tristemente recordado entre los partidos políticos dominantes que dieron uso de sus facultades gubernamentales para acaparar toda la política y generar una hegemonía en el poder durante muchos años.

Ahora bien, en el primer artículo hallado con respecto a la constitución de 1886, denominado Un Nuevo Mundo Político, su autor Jorge Orlando Melo establece distinciones entre las expresiones República, republicana y republicanismo; donde la primera guarda estrecha relación con el significado de nación, está la expone como sinónimo de una sociedad, continuó entonces con la palabra republicana donde simplemente le da significado a una univer-

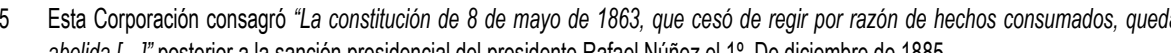

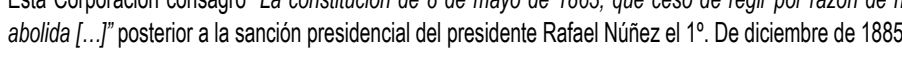


sidad y finaliza con la palabra republicano para hacer apología de un partidario del partido conservador. (Melo, s.f)

Queda entonces, la República de Colombia, supeditada a distintas variantes: una nación azotada por una voraz violencia, un Estado con instituciones poco sólidas, crisis tras crisis, e incertidumbre.

Todo esto se ve plasmado en un referente normativo que poca reflexión supone sobre los términos que indistintamente usa para dar cuenta de Colombia como nación, como país, como democracia o como república, que para esta parece no existir gran diferencia. Que si es lo mismo, o no, queda a suspensión del desarrollo del segundo y tercer capítulo de esta investigación pero lo cierto es, que el desarrollo dogmático de esta Carta Política es insuficiente para dar descripción precisa de los preceptos republicanos objeto de estudio.

\section{Reformas de la Constitución Política de 188}

Sería errado afirmar que la Constitución expedida en 1886 llega impoluta hasta el año de su derogación absoluta. Por el contrario, fue reformada en numerosas ocasiones, sea por capricho del legislador, o inminente necesidad, pero se hizo.

Al revisar estas reformas (57 para ser exactos), se halló reiterativamente el uso de la expresión República, principalmente para dar razón de cargos de gran prestigio en el orden nacional (Presidente de la República, vicepresidente de la República, senador de la República, etc.); o para referirse al conglomerado humano asentado en un mismo territorio, llamado país. Pero poco, o nada, responde a una delimitación del discurso republicano; evocaron también la República para declarar un elemento republicano insignia: tridivisión de poderes. Dicho de forma exacta, así:

Artículo 52.- Son ramas del Poder Público la Legislativa, la Ejecutiva y la Jurisdiccional. El Congreso, el Gobierno y los jueces tienen funciones separadas, pero colaboran armónicamente en la realización de los fines del Estado. (Reformas a la Constitución de 1886, s.f.)
En el acto legislativo № 01 del agosto 5 de 1936, se incluye la palabra "República" pero con aras de referirse al territorio concerniente al lugar donde han de nacer los considerados nacionales, ies acaso para el legislador, difuso el concepto de República y Territorio? Entendido este último como un elemento más en la figura estatal. Del mismo modo, se añaden otras disposiciones en cuanto a la regulación de la Educación y las creencias, estas últimas comprendidas bajo la titularidad de "moral cristiana", contraria a ella, está mal, es inadmisible. ¿Puede un Estado hacerse creces de República en medio de una limitación de orden netamente ideal e intrínseco a la percepción que cada colombiano tenga?

\section{La República en: Asamblea Nacional Constituyente.}

\section{Antecedentes de Investigación.}

Al establecer antecedentes sobre la implementación de la república en Colombia a partir de la asamblea nacional constituyente de 1991, más específicamente las investigaciones antes realizadas al presente proyecto con respecto a "la república", son escasas. Cabe resaltar que existen varias donde concibe la asamblea nacional constituyente, sin instituir una línea que se rija a la república.

En primer lugar se tiene que en Febrero 6 del 2012, fue presentado en la revista Opinión Jurídica, el trabajo sobre; el ordenamiento territorial en la asamblea nacional constituyente de 1991, lectura socio-jurídica desde el nivel intermedio del gobierno por Liliana Estupiñan Achuri, como resultado del proyecto de investigación la constante estructura centralista de la forma de estado colombiana, adscrito a la línea de investigación territorio, descentralización y democracia del grupo de derecho público de la facultad de jurisprudencia de la Universidad del Rosario.

La investigación responde al interrogante del por qué el modelo unitario ha sido la constante histórica de la forma de Estado que ha tenido Colombia inspirándose en la tesis planteada por Valencia con respecto a las distintas estructuras del estado colombiano, entre estas, citó expresiones como presidencialismo, confesionalismo, libertades públicas, republicanismo y centralismo. Sin embargo, esta misma investigación establece que el modelo adoptado fue el unitario. (Estupiñán Achuri, 2012) 
Sobre la república, o como bien lo establece la investigación el republicanismo unitario, establece:

En el proceso pre y constituyente de 1991 también se encuentran herramientas para corroborar la constante centralista del Estado colombiano. Asi, la égida del republicanismo acudió una vez más a este enfoque, muy a pesar de los vientos que corrieron en pro de otros modelos "en teoría" más descentralizados. En última instancia, la opción territorial de la Asamblea fue la misma de la Constitución de 1886. Un buen momento desaprovechado en razón de los miedos. (Estupiñán Achuri, 2012, pág. 19)

En esta misma labor de consulta, se encontró el trabajo de investigación titulado El poder constituyente "extraordinario" como dispositivo generador de responsabilidad patrimonial del estado: Implicaciones de la asamblea nacional constituyente -ACN- en la configuración de la noción del modelo constitucional introductorio con la carta política de 1991"; presentado el 3 de marzo del 2012 por Edwin Hernando Alonso Niño.

Esta investigación establece que el nuevo modelo constitucional latinoamericano que ha sido adoptado por Colombia es resultado de, "la migración de ideas" que hace parte del desarrollo del derecho constitucional y la autodeterminación jurídica. (Alonso Niño, 2012)

\section{La República en actas de la Asamblea Nacional Constituyente}

Colombia es, entonces, un ejemplo de cómo un gobierno, una nación y un sistema judicial exhausto, busca a toda costa mecanismos que salvaguarden garantías, derechos, estabilidad de sus instituciones, reafirmación de sus principios y le dé nuevos aires a un panorama nacional ensordecedor. Que, si la reforma constitucional era la alternativa más idónea o no, es motivo de interrogantes más hipotéticos, pues la realidad es que se consolidó, y se hizo en aras de convertir los compromisos plasmados de las nuevas normas constitucionales en una realidad efectiva y en evitar que el sistema político vuelva a incurrir en los vicios que caracterizaban al régimen anterior.

Para efectos de describir elementos republicanos contenidos en el desarrollo de esta Asamblea, fue necesario leer a detalle los debates que acarrean los proyectos presentados por los distintos constituyentes. Entre los cuales, se pueden destacar los transcritos a continuación,

Ha sido y debe ser el Artículo Primero de la Constitución una definición clara de la clase de Nación que se es y se pretende ser. Lo que se es y lo que se desea ser. Somos con evidencia una Nación y la Nación históricamente ha adoptado la forma republicana de gobierno. (Zalamea Costa, 1991)

Así pues, uno de los constituyentes ya delimitó a Colombia, en el proyecto número 35 , como una república, pero es escasa o nula su explicación sobre lo que quiso decir al hacerlo.

En cambio, Jaime Arias, en su proyecto número 75, sobre la forma de Estado, fue un poco más dilatado al distinguir forma de Estado, de forma de Gobierno, así:

Lo Unitario hace relación a la forma de Estado. Mientras que "República" lo hace a la forma de Gobierno. El Estado es el poder político, que se ejerce mediante Instituciones que de acuerdo a su organización y estructura es la forma de gobierno. (Arias López, 1991)

Más adelante, en el acta número 87, Guillermo Perry Rubio interviene en proyecto sobre las entidades territoriales y su ordenamiento, aluden a ellas como partes y entidades de la república de la siguiente manera:

Son entidades territoriales de la república, la nación, las regiones,

los departamentos y los municipios. (Perry Rubio, 1991)

Sin embargo, en la exposición de las razones no ahonda en el término, y supone más una equivalencia entre república y país.

En la relatoría de la sesión inagural se recitó un discurso por parte de los presidentes de la Asamblea Nacional constituyente, Aida Abella y Carlos Abello, este último declaró: "La Asamblea Constitucional está llamada entonces a cumplir una tarea de rescate y salvación. Sin romper, desde luego, la estructura democrática de la República. Por lo contrario: asegurando fortaleciendo la independencia, la estabilidad, la dotación y la celeridad del poder jurisdiccional" (Abello, 1991) 
Continuamente el presidente colombiano del entonces, César Gaviria (1991), se dirigió al auditorio manifestando: "Alguien dijo hace más de un siglo que "las repúblicas deben ser autoritarias, so pena de incidir en permanente desorden y aniquilamiento en vez de progresar"

Se encontró que, en repetidas ocaciones, distintos constituyentes mencionaban todas las caracteristicas del Estado colombiano, mismas características que comprende ser una república pero sin distinguir el significado que tendría ser un país republicano, como fue el caso de Aída Abella que en plenaria de la Asamblea Nacional Constituyente del 18 de febrero de 1991 en la que expuso:

La solución a la crisis institucional que vive Colombia implica la transformación del Estado y por ello proponemos que éste debe tener las siguientes características: un Estado social de derecho democrático y pluralista, que se fundamente en la soberanía popular que respete eficazmente los derechos humanos y las garantías individuales. Un Estado que respete el derecho de las minorías, el ejercicio de la crítica y la opinión, promoviendo la tolerancia, el derecho a la información ciudadana y la libertad de expresión. (Abella, 1991)

A su vez, en la intervención de Francisco Rojas Birry (1991) dirigida a reformar el Articulo 1o de la Constitución, propuso que fuese así: "El pueblo colombiano es pluralista, de naturaleza multiétnica y pluricultural. En él reside exclusivamente la soberania y de ella emanan los poderes públicos que se ejercerán en los términos que esta Constitución"

Omitiendo de este modo, entre muchas otras distinciones, el establecimiento de Colombia como República pero resaltando las características de país multiétnico y pluricultural que tendría la Constitución.

\section{La República en: Constitución Política de 1991}

\section{Antecedentes de Investigación}

El primer documento examinado fue Estado del Arte sobre la Reforma a la Justicia (1191-2011), el cual, contiene un breve estudio sobre el contexto del año 1991, en el que fue expedida la actual Constitución colombiana, y para el caso de nuestro interés, se dio lugar a la concepción de República. En éste documento, solo se deja claro que las decisiones tomadas a través de la constitución de 1991 representaron para el país un gran cambio en la forma de gobierno y organización del Estado, sin distinguir una, de otra. (Centro de Documentación Judicial Corte Constitucional, 2015)

Luego de un rastreo documental a las fuentes que se encuentran en éste documento, se determina que cada uno de éstos, si bien hablan de la constituyente y algunas materias importantes dentro de ésta, no abordan, como máximo bordean, el tema de la República o de las consecuencias de habla de esta. En cada tema que se toca se entiende una influencia de la República, tal como el asunto del poder soberano, la acción de tutela y normas internacionales protectora de derechos, sobre lo cual, a continuación, se dejará rastro. Sin embargo, nada a profundidad sobre el tema a estudiar en este caso. (Comisión Colombiana de Juristas, 2003)

En el artículo "La Constitución de Colombia de 1991 y sus enemigos. El fracaso del consenso constitucional" por Jorge Andrés Hernández se pretende describir los argumentos que soportarían un fracaso constitucional sobre la constituyente de 1991, por lo que su contenido pretende llevar a un convencimiento negativo sobre la efectividad y formación de la actual constitución. Encontramos en éste documento algunos puntos referentes a la República, si bien no son muy profundos, y en virtud de la poca información que se encuentra sobre este tema, se transcribe a continuación,

"Columna editorial del diario El Tiempo, con el título de La otra batalla: "Hoy se va a realizar la más importante elección de la historia del país. Desde la fundación de la República, los colombianos hemos participado en infinidad de debates electorales y hemos votado en ellos periódicamente para elegir desde primeros mandatarios hasta concejales de los más modestos municipios" (El

Tiempo 1990a, 4-A)."

\section{República: preceptos vigentes hoy}

Es en este punto, de las garantías y libertades, en el que compaginan conceptos muy particulares, especialmente filosóficos, pues a la larga, la República a la que se alude con frecuencia y se saluda al lector en la Carta Política vigente, no es otra cosa que un régimen político legalmente constituido y fundado sobre principios racionales que se sintetizan en el tríptico 'libertad, igualdad, fraternidad'. Como conjunto de principios, ideas y prácticas, tiene su fuente en 
el movimiento iluminista que pone el derecho natural y la teoría del contrato como fuente de la soberanía y base de la legitimidad. Tanto Montesquieu como Rousseau conciben el gobierno republicano como aquel en el cual el poder soberano es ejercido por el pueblo y se gobierna al amparo de la ley. (LEFORT, 1999).

El principal problema con el empleo indiscriminado de la expresión es la reiterada referencia a la incapacidad de la República de ser un principio de orden político o un referente claro de la identidad nacional, pues es esta la que, en última instancia, se encuentra soslayada por creencias erradas de República, vivencias cotidianas alejadas por brechas distanciadas del término lato.

\section{LA REPÚBLICA DESDE PLATÓN, JEAN BODINO Y EMMANUEL KANT.}

\subsection{La República - Platón}

En este libro, Platón intenta enmarcar una forma en que las personas puedan vivir bien, para ello, plasma un diálogo entre atenienses y su maestro, Sócrates bajo el método de la mayéutica.

En este orden de ideas, el primer tema tratado fue la Justicia, pues, aunque no hay una definición concreta de esta, se acordó que es la virtud que permite a los hombres vivir bien, afirmando así, que la ciudad debe ser justa.

A lo largo del libro, los personajes intentan llegar a un consenso sobre el concepto de justicia, primero Céfalo afirma que es decir la verdad y devolver a cada uno lo que dé él se haya recibido, aquí Sócrates difiere, pues en ocasiones, eso que se recibió no tiene un buen objeto, por lo que Sigmoides asevera que se da a cada quien lo que es apropiado, seguidamente se manifiesta Polemarca diciendo que lo justo es hacer bien al amigo que es bueno y mal al enemigo que es malo, Sócrates respondió que el justo nunca hace el mal y se derriban los conceptos de Justicia antes mencionados, en lo seguido de la conversación hablan de la Justicia como un oficio pero luego caen en cuenta que es algo más amplio pues impregna a cada uno de estos. (Platón, 1984)

Dado que una ciudad justa es donde existe la división de trabajo que cada persona se dedique a un trabajo que refleje sus capacidades e intereses, esta ciudad entonces, deberá dividirse en clases sociales, la primera de ellas en: artesanos, aquellos que tienen un conocimiento específico sobre una actividad que será la que más les guste; los guerreros, que son irascibles, es decir que los motiva el espíritu y no el dinero, no deben tener un gran sueldo porque eso haría que todos quisieran ser guerreros, estos deberán ser educados con música para que se acostumbren a lo bello y quieran verlo en los hombres y con gimnasia para que tengan un buen físico, Sócrates considera muy importante la educación y por los guerreros recibirla de esta forma en especial son los que poseen el alma más fina y de entre ellos deberá elegirse al filósofo rey que por su experiencia será mayor de edad, además deberá ser sabio y prudente, protegerá la ciudad con la ayuda de los guerreros quienes lo largo de su formación serán probados en cuanto a la capacidad de resistir los alicientes del placer y el miedo, los que más sobresalgan ascenderán al rango de guardianes que son varios pero en todo caso un número reducido. (Platón, 1984)

La ciudad-Estado deberá también tener ciertas virtudes: Sabiduría que residiră en los artesanos pero para su actividad en específica y en el gobernante que constará de un conocimiento amplio que abarque el bien de la ciudad en su totalidad y el coraje como elemento dominante en el alma de los guerreros, así como la templanza, que no se limita a una sola clase sino que transversa entre todas, como un acuerdo con respecto a quien gobernará; y finalmente la justicia, que posibilita las otras tres virtudes. (Platón, 1984)

\section{Los seis libros de La República - Jean Bodino}

En los primeros capítulos, Bodino hace referencia a la finalidad de la República bien organizada y los elementos que la conforman; para ello, establece una de la República, así: "un recto gobierno de varias familias, y de lo que les es común, con poder soberano", determinando que el recto gobierno es aquel que es justo y leal. (Bodino, 2006)

El autor se basa en el concepto de felicidad de Aristóteles en tanto que es algo compuesto por diversos elementos, de la misma manera lo es la República, ya que esta debe constar de unos componentes principales como el territorio, el alimento, la materia prima y los súbditos, así mismo también debe contar con componentes secundarios (a los cuales el autor se refiere como "comodidades") tales como medicinas y metales, puesto que si los hombres que conforman la República son sabios y felices entonces la República en si 
misma será Feliz, es por esto que el elemento humano es el pilar principal de una república bien organizada, y como el hombre está en constante cambio, también lo estará la república y es por esto que requiere de las acciones de entendimiento, que le permiten al hombre desarrollar sus virtudes, sin embargo el hombre necesita también de las acciones ordinarias pero no puede basarse en dichas acciones para fundar sus contemplaciones. (Bodino, 2006)

El fin de la República bien organizada está en las contemplaciones, y para ello cada República debe forjarse en el equilibrio de estas acciones permitiendo que la republica teniendo en cuenta sus fines alcance su felicidad; continua señalando lo que es la administración doméstica definiéndola como "el recto gobierno de varias personas y de lo que les es propio, bajo la obediencia de un cabeza de familia" y las diferencias entre la república y la figura de la familia, puesto que en la definición de República precisada se hace referencia a dicha figura, debido a que esta es el origen principal de toda república, al ser su elemento fundamental, la familia conformada por un grupo de personas, entre las cuales está el cabeza de hogar quien es el que tiene el mando y da las ordenes, es decir quien tiene el poder, las demás personas le deben obediencia a este jefe, ahora bien, este poder domestico es análogo al poder soberano, donde una persona tiene la facultad de tomar las decisiones y los súbditos deben someterse.

Así el recto gobierno de la casa es el verdadero modelo del gobierno de la República, de este modo, la república estará bien si las familias están bien gobernadas, además de la soberanía es necesario que exista algo colectivo y de carácter público como lo son el patrimonio, las leyes, las penas, las costumbres, entre otros, puesto que No existe República si no hay nada público; sin embargo para que existan cosas públicas es necesario que existan cosas particulares debido a que sería contrario a las leyes naturales. (Bodino, 2006)

\subsection{La Paz Perpetua - Emmanuel Kant}

Kant, lejos de haber sido un idealista descabellado, fue un ferviente precursor de la República garantista, pacifista y, sobre todo: que consagre la Soberanía Popular. Ejemplo claro de ello es, que, para declarar Guerra a otro Estado, en un marco de genuino republicanismo, debe ser la Nación en consenso quién lo decida por ser esta la que verá lesionados sus derechos; en contravía de
Bodino, quién nos expresó con válidos argumentos que deben concentrarse decisiones de esta naturaleza a manos de una sola persona. Y luego, ¿No son acaso estos derechos, los que se consagran y protegen en una auténtica República? Efectivamente, esto quiso decir Kant.

Para Kant, en su obra la paz perpetua, asemeja a la paz como una necesidad, un deseo generalizado, el cual se materializara por el sacrificio de una u otra persona en busca de hacerla cumplir, sin embargo, y aun con el deseo de mantenerla, la dificultad radica principalmente en hacerla cumplir para toda la comunidad, y es de conocer que ante un ataque contra el interés global, estos mismos defenderán su interés global y su derecho natural, si bien es cierto, al momento de esclarecer una guerra, los actores principales

Para el autor "Abstenerse de romper las hostilidades no basta para asegurar la paz, en este momento radicaría en aquello que no se quiere hacer, pensamiento individualista, conociendo que el interés general deberá primar y cumplir el deber hacer.

Deben existir también características específicas, intrínsecas a cada Estado, las cuales, permitirán atribuir ideales y principios, además de materializar sus fines, manteniendo la convivencia ciudadana, aclarando a su vez, que los Estados no deben tener convicciones 0 anhelos propios, sino conservar una organización que permita asegurar el bienestar de la comunidad global.

En la República deseada, se concentran los intereses de la nación, y será la misma nación quien tome las decisiones que defiendan el derecho de paz, todo ellas con base en una Constitución, que para ser republicana deberá contener como fundamentos los siguientes principios:

- Principio de la libertad de los miembros de una sociedad como hombres

- Principio de la dependencia en la que todos se hallan de una única legislación común como súbditos

- Principio de la igualdad de todos como ciudadanos.

Para finalizar, Kant alude que uno de los requerimientos base para hablarse de Constitución republicana era la subordinación de la población para con la legislatura de su país, asi como la igualdad, y libertad. (Kant, s.f.) 
3. CONTRASTE DIFERENCIADOR ENTRE LA REPÚBLICA DESDE LA

PERSPECTIVA DE LA CONSTITUCIÓN POLIITICA DE 1991 Y DE LOS AUTORES ESCOGIDOS: PLATÓN, JEAN BODINO Y EMMANUEL KANT

\begin{tabular}{|c|c|c|c|c|}
\hline COMPONENTE & $\begin{array}{l}\text { CONSTITUCIÓN POĹTITCA } \\
\text { COLOMBIANA DE } 9991\end{array}$ & $\begin{array}{l}\text { LAREPÚBLLCA } \\
\text {-PLATON } \\
\end{array}$ & $\begin{array}{l}\text { LIBROS DE LA REPÚBLICA- } \\
\text { JEAN BODINO }\end{array}$ & $\begin{array}{l}\text { LA PAZ PERPETUA- } \\
\text { ENMANUEL KANT }\end{array}$ \\
\hline $\begin{array}{l}\text { DEFINIIIÓN DE } \\
\text { REPUUBLICA }\end{array}$ & $\begin{array}{l}\text { Elemento característico del } \\
\text { territorio y la soberanía } \\
\text { estatal }\end{array}$ & $\begin{array}{c}\text { La república es } \\
\text { aquella que divide } \\
\text { las clases sociales en } \\
\text { artesanos, guerreros y } \\
\text { guardianes. }\end{array}$ & $\begin{array}{l}\text { Un recto gobierno de varias } \\
\text { familias, yde lo que les } \\
\text { comunn, con poder soberano. }\end{array}$ & $\begin{array}{c}\text { Republicanismo; Es el } \\
\text { prinicipio político de la } \\
\text { separación del poder } \\
\text { ejecutivo, Gobierno y } \\
\text { legislativo. }\end{array}$ \\
\hline CARACTERISTICAS & $\begin{array}{l}\text { Constitución ecológica. } \\
\text { Consagra derecchos y } \\
\text { deberes. } \\
\text { Consagra soberania popular. } \\
\text { Tridivisision de poderes. } \\
\text { Inclusión de la mujer. }\end{array}$ & Inclusión de la mujer. & $\begin{array}{c}\text { Territorio } \\
\text { Súbditos } \\
\text { Materia prima } \\
\text { Soberanía }\end{array}$ & $\begin{array}{l}\text { Es adecuada al derecho } \\
\text { de los hombres. } \\
\text { Pensada por políticos } \\
\text { morales. } \\
\text { Propicia para la paz } \\
\text { perpetua. }\end{array}$ \\
\hline $\begin{array}{c}\text { PRIMER } \\
\text { MANDATARIO }\end{array}$ & $\begin{array}{l}\text { LA RAMA EIECUTIVA: } \\
\text { Art 188: el presidente de } \\
\text { la Republica simboliza } \\
\text { la unidad nacional yal } \\
\text { jurar el cumplimiento de la } \\
\text { constitución y de las leyes, } \\
\text { se obliga a garantizar los } \\
\text { derechos y l libertades de } \\
\text { todos los colombianos }\end{array}$ & Filósofos reyes. & 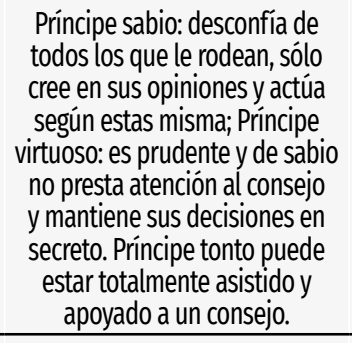 & $\begin{array}{l}\text { Jefe de Estado que } \\
\text { debía ser un ciudadano } \\
\text { y no un amo. }\end{array}$ \\
\hline $\begin{array}{l}\text { ADMINISTRADO- } \\
\text { RES DE JUSTICIA }\end{array}$ & $\begin{array}{l}\text { Jueces que forman parte } \\
\text { de los tribunales de orden } \\
\text { superior en cada pais. }\end{array}$ & Guardianes. & $\begin{array}{l}\text { Aquel oficial que tiene } \\
\text { mando en la repupblica, son } \\
\text { la principal fuented de la } \\
\text { republica, son exactamente } \\
\text { en quien confía el soberano } \\
\text { para asignar mandatos } \\
\end{array}$ & \\
\hline $\begin{array}{l}\text { FIN DE LA } \\
\text { REPUBLICA }\end{array}$ & 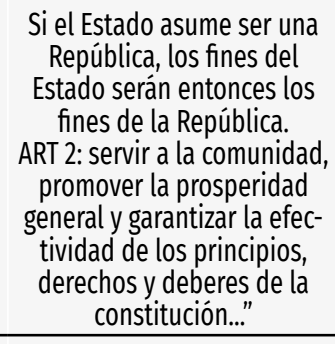 & Bien y justicia. & $\begin{array}{l}\text { Es la virtud y el objetivo es } \\
\text { hacer a los subdoditos buenos } \\
\text { yvirtuosos, para llegar a su } \\
\text { mision debe dejaral aúbublico } \\
\text { todos sus cometidos. }\end{array}$ & \\
\hline GOBERNADOS & Pueblo. & Artesanos. & $\begin{array}{l}\text { Súbditos, trabajaban en } \\
\text { colaboración }\end{array}$ & $\begin{array}{l}\text { Todos, aquellos depen- } \\
\text { dientes de una única } \\
\text { legislación, denomina- } \\
\text { dos súbditos. }\end{array}$ \\
\hline $\begin{array}{l}\text { TIPOS DE } \\
\text { GOBIRNO }\end{array}$ & $\begin{array}{l}\text { Establece en su artículo No. } \\
1 \text { que es una "Democracia } \\
\text { participativa" y se desarro- } \\
\text { lla a lo largo del articulrado } \\
\text { de la Constitución. }\end{array}$ & $\begin{array}{l}\text { Aristocracia, es la } \\
\text { forma de Gobierno } \\
\text { ideal, las decisiones } \\
\text { son tomadas por } \\
\text { personas capacitadas } \\
\text { (pensadoroses filosofos, } \\
\text { que tenias cualidades } \\
\text { ynaturalezas innatas } \\
\text { para alcanzar esta } \\
\text { capacidad). }\end{array}$ & 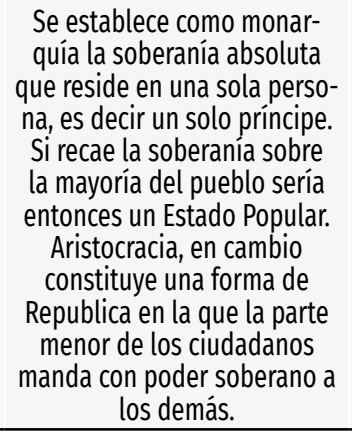 & $\begin{array}{l}\text { Republicanismo y } \\
\text { despotismo. }\end{array}$ \\
\hline
\end{tabular}

\begin{tabular}{|c|c|c|c|c|}
\hline COMPONENTE & $\begin{array}{l}\text { CONSTITUCIÓN POLITICA } \\
\text { COLOMBBANA DE } 1991\end{array}$ & $\begin{array}{l}\text { LAREPÚBLICA } \\
\text {-PLATÓN }\end{array}$ & $\begin{array}{l}\text { LIBROS DE LA REPÚBLICA- } \\
\text { JEAN BODINO }\end{array}$ & $\begin{array}{l}\text { LA PAZ PERPETUA- } \\
\text { ENMANUEL KANT }\end{array}$ \\
\hline JUSTICIA & $\begin{array}{l}\text { Aparece como valor en el } \\
\text { preámbulo o como princioio } \\
\text { en articulos como los } \\
\text { referentes a deberes de los } \\
\text { ciudadanos,s, fines de los } \\
\text { organos que lo constituyen. }\end{array}$ & $\begin{array}{l}\text { La justicia es el valor } \\
\text { que debe impregnarlo } \\
\text { todo ya que no es una } \\
\text { labor oun oficio sino } \\
\text { una guia apara actuar } \\
\text { en los diferenttes } \\
\text { escenarios }\end{array}$ & $\begin{array}{l}\text { Principio rector de los } \\
\text { Organos que consoliden toda } \\
\text { Repubblica, aparece junto a } \\
\text { otros, como leattad y unidad. }\end{array}$ & \\
\hline SOBERANíA & 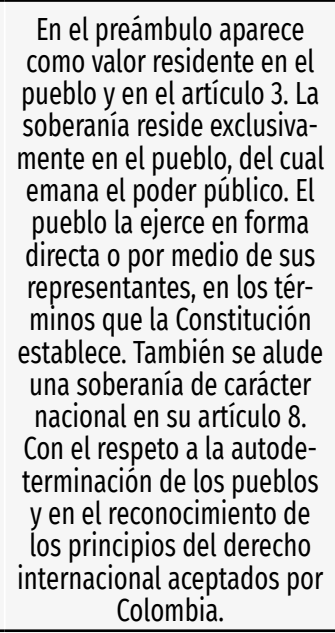 & & 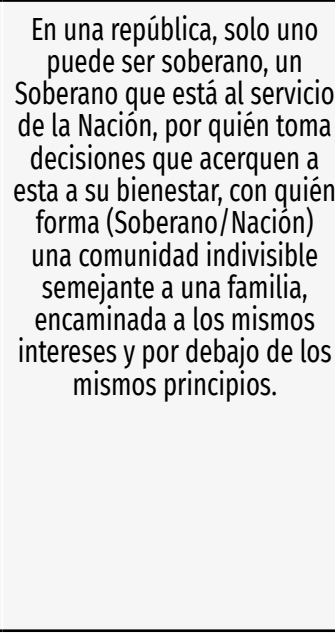 & Reside en el pueblo. \\
\hline $\begin{array}{c}\text { ÓRGANOS } \\
\text { COLEGIADOS }\end{array}$ & 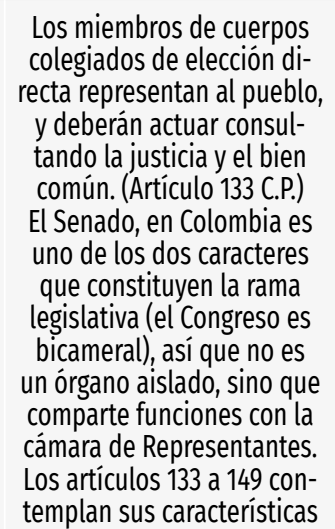 & $\begin{array}{l}\text { Solo contempla como } \\
\text { organo colegiado la } \\
\text { aristocracia. }\end{array}$ & 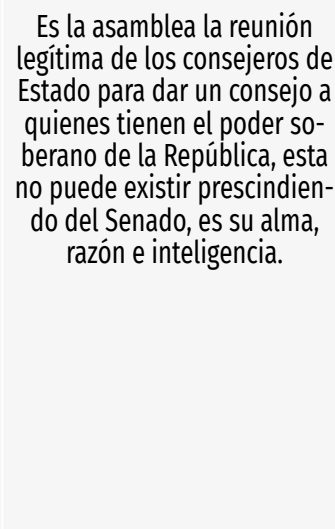 & \\
\hline $\begin{array}{l}\text { ELEMENTOS } \\
\text { ESTATALESY } \\
\text { CONSTITCCIO- } \\
\text { NALES }\end{array}$ & $\begin{array}{l}\text { Se encuentran conteni- } \\
\text { dos implicitamente en Ia } \\
\text { Constitución y distribui- } \\
\text { dos a lo largo de la Carta } \\
\text { Polititaca, principalmente en } \\
\text { el preámbulo donde esta- } \\
\text { blece que colombia es un } \\
\text { Estado Social de Derecho. Se } \\
\text { habbla de: territorio, nacion, } \\
\text { soberania y reconocimiento } \\
\text { internacional. }\end{array}$ & & $\begin{array}{l}\text { El territorio, la soberanía (no } \\
\text { de la lacioion, sino del gober- } \\
\text { nante, que no es limitada, } \\
\text { ni en poder, ni ier erspon- } \\
\text { sabilidad, ni en tiempo) el } \\
\text { alimento, la materia primay y } \\
\text { los subditos, asi como otras } \\
\text { "comodidades" (metales, } \\
\text { medicinas, etc.). }\end{array}$ & 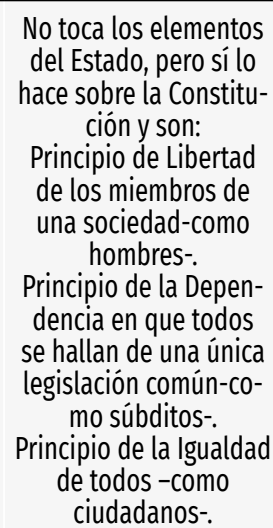 \\
\hline
\end{tabular}




\begin{tabular}{|c|c|c|c|c|}
\hline COMPONENTE & $\begin{array}{l}\text { CONSTITUCIÓN POĹLITICA } \\
\text { COLOMBIANA DE } 1991\end{array}$ & $\begin{array}{l}\text { LAREPÚBLICA } \\
\text {-PLATÓN }\end{array}$ & $\begin{array}{l}\text { LIBROS DE LAREPÚBLICA- } \\
\text { JEAN BODINO }\end{array}$ & $\begin{array}{l}\text { LA PAZ PERPETUA- } \\
\text { ENMANUEL KANT }\end{array}$ \\
\hline $\begin{array}{l}\text { DIVISIÓN DE } \\
\text { PODERES }\end{array}$ & $\begin{array}{l}\begin{array}{l}\text { Legislativo, ejecutivo y } \\
\text { judicial. }\end{array} \\
\text {. }\end{array}$ & $\begin{array}{l}\text { La división de poderes } \\
\text { se da entre: guerre- } \\
\text { ros, guardianes y un } \\
\text { filósofo rey. }\end{array}$ & & $\begin{array}{l}\text { No pueden ser simultá- } \\
\text { neamente legislador y } \\
\text { ejecutor de la voluntad. } \\
\text { (poder ejecutivo, sepa- } \\
\text { rado del legislativo.) }\end{array}$ \\
\hline PAZ & 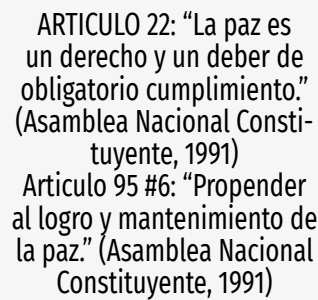 & & & $\begin{array}{l}\text { La Constitución repu- } \\
\text { blicana es propicia para } \\
\text { la paz perpetua. }\end{array}$ \\
\hline
\end{tabular}

\section{CONCLUSIONES}

La idea de Estado como República no tuvo génesis en la Asamblea Nacional Constituyente, en cambio, fue asociada Colombia como una República por vez primera en la Constitución Política de Rionegro en 1863, retomada en la Constitución Política de 1886 y asumida nuevamente en la Carta Política de 1991.

Denominar a Colombia como una República no fue tema objeto de debate para los constituyentes, no generó controversia, y fue incluido así en el artículo número uno por iniciativa de uno de los constituyentes (Carlos Zalamea Costa), sin mayor discusión entre los demás presentes.

Los constituyentes admitieron a Colombia como una República pero no ahondaron en su justificación y tampoco, establecieron parámetros con ocasión de ella. No es motivo de discusión que hay vestigios de República en lo que promulga nuestra Carta Política vigente pero con ausencia de debate sobre la forma de gobierno que debía asumirse, pues no consta en las actas.

Un común denominador entre la Carta Política de 1886 y de 1991, es el empleo de la noción República sin hacer mayores distinciones de su signficado, confundiéndolo así, con conceptos como país, territorio y Estado, asumiendo que semánticamente la república es equivalentes con estas locuciones.

Aunque son múltiples los trabajos de investigación adelantados en torno a la Asamblea Nacional Constituyente y las características de nuestra Constitución, estos no hacen énfasis en el discurso republicano de la misma, por lo que, los insumos académicos para esta investigación fueron precarios.

Las definiciones de República de los tres (3) autores reseñados son variantes, sujetos a su contexto histórico, sin embargo, la asumen en conjunto como una forma de gobierno, caracterizadando su idea de república con principios fundantes y luego, desarrollando un medio de ejecutarlos, como bien ocurre con la Constitución Política de Colombia al dividirse en una parte dogmática y otra, orgánica.

La Constitución política de 1991 es congruente de manera implícita con los preceptos Republicanos establecidos por los autores estudiados, sin embargo su justificación en el empleo de la noción republicana no es clara.

El empleo indiscriminado de la expresión República en el marco de Constitución Política de 1991, la aleja de referenciarse como principio de orden político o un referente claro de la identidad nacional, por ejemplo: asociar sin el menor percance la democracia con la República, asumiendo el sufragio como expresión republicana, en lugar de asociarla como recurso del modelo democrático participativo.

\section{REFERENCIAS}

Abella, A. (1991). Gaceta Constitucional. Obtenido de Sesión lenaria gaceta N 18 http://www.lexbasecolombia.net/lexbase/jurisprudencia/Gacetas\%20Constitucionales/g018.pdf

Abello, C. (1991). Gaceta Constitucional . Obtenido de Sesión inaugural de la Asamblea Nacional Constituyente : http://www.lexbasecolombia.net/lexbase/jurisprudencia/Gacetas\%20Constitucionales/g001.pd

Alonso Niño, E. H. (2012). El poder constituyente "extraordinario" como dispositivo generador de responsabilidad patrimonial del estado: Implicaciones de asamblea nacional constituyente en la configuración de la noción del modelo constitucional introductorio con la CP del 9

Arias López, J. (1991 de marzo de 1991). Banco de la República-biblioteca virtual Luis Angel Arango. Obtenido de http://www.banrepcultural.org/blaavirtual/ANC/ brblaa857249_342.044_A74p.pdf

Banco de la República. (15 de Septiembre de 2016). Banco de la República Actividad Cultural. Obtenido de http://www.banrepcultural.org/bogot/evento/de-toda-la-gente?platform=hootsuite

Birry, F. R. (1991). Gaceta Constitucional. Obtenido de http://www.lexbasecolombia. net/lexbase/jurisprudencia/Gacetas\%20Constitucionales/g001.pd

Bodino, J. (2006). Los seis libros de la república. Tecnos.

Centro de Documentación Judicial Corte Constitucional. (2015). Corte Constitucional. Obtenido de http://www.corteconstitucional.gov.co/inicio/Constitucion\%20 politica\%20de\%20Colombia\%20-\%202015.pd 
Estupiñán Achuri, L. (2012). El ordenamiento territorial en la asamblea nacional constituyente de 1991, lectura socio-jurídica desde el nivel intermedio del gobierno. Revista Universidad de Medellín.

Gaviria, C. (1991). Gaceta Constitucional. Obtenido de Sesión inaugural de la Asamblea Nacional Constituyente: http://www.lexbasecolombia.net/lexbase/jurisprudencia/ Gacetas\%20Constitucionales/g001.pd

Kant, E. (s.f.). Biblioteca Virtual Universal. Obtenido de http://www.biblioteca.org.ar/ libros/89929.pdf

LEFORT. (1999).

Melo, J. O. (s.f). Un nuevo mundo político. Nueva historia de Colombia.

Ortiz Leroux, S. R. (2007). República y republicanismo: una aproximación a sus itinerarios de vuelo. Argumentos( ISSN 0187-5795.), 20-53. Recuperado el 2017 de Abril de 06, de http://www.scielo.org.mx/scielo.php?script=sci_arttext\&pid=S0187-5795200

Perry Rubio, G. (8 de Marzo de 1991). Banco de la República - Biblioteca virtual Miguel Ängel Arango. Obtenido de http://www.banrepcultural.org/blaavirtual/ANC/ brblaa857265_336.20986_V39p.pdf

Platón. (1984). La República. Medellin: Bedout S.A.

Reformas a la Constitución de 1886. (s.f.). Obtenido de Biblioteca virtual Miguel de Cervantes: http://admonpublica.org/page/images/Documentos/Constituciones/1886_constitucin_repblica_colombia_reformas.pdf

Ripoll, J. L. (2016). El movimiento estudiantil de 1989 y la Séptima Papeleta. De toda la gente - Banco de LA República.

Tascón, T. E. (2000). Historia del Derecho Constitucional Colombiano. Pereira: Litoalfa.

Uribe, M. T. (1987). La Constitución de 1886 como respuesta a la crisis del modelo federal y a la confrontación nación-región en Colombia. 6-9.

Villavicencia, S. (2003). La (im)posible República. Filosofía política contemporánea, Ciudad Autónoma de Buenos Aires. Obtenido de La (im)posible República: http:// biblioteca.clacso.edu.ar/clacso/se/20100603120826/7villavicencio.pdf

Zalamea Costa, A. (7 de Marzo de 1991). Banco de la República - Biblioteca virtual Luis Ángel Arango. Obtenido de Artículo primero de la Constitución: http://www. banrepcultural.org/blaavirtual/ANC/brblaa857260.pdf 